\title{
Effect of alloy surface composition on release of elements from dental casting alloys
}

J.C. WATAHA \& C.T. MALC OLM * Department of Oral Rehabilitation, Medical College of Georgia, and *Department of Materials Science and Engineering, University of Michigan, Ann Arbor, U.S.A.

\begin{abstract}
SUMMARY The release of elements from dental casting alloys is a continuing concern because of the potentially harmful biological effects the elements may have on local tissues. The surfaces of the alloys appear to be most important in controlling the release of these elements. In the current study, the surfaces of high-, reduced-, and no-gold dental alloys were analysed by $\mathrm{X}$-ray photoelectron spectroscopy before and after they were exposed to a biological medium for up to $96 \mathrm{~h}$. The goal was to relate the release of elements from these alloys to their surface composition, and to determine the depth of the effect of the medium. The depth of the effect of the exposure was determined by argon milling of the alloy surface after exposure to the medium. Elements that were released into the medium were measured
\end{abstract}

by means of atomic absorption spectroscopy. The release of elements from alloys was greater when the atomic ratio of noble to non-noble elements at the surface was less than 1 . The depth of the effect of the medium varied with the alloy, but was always less than $100 \AA$. The surface composition was significantly different from layers only $5 \AA$ below. It was concluded that the surface concentration of noble elements is important in controlling the release of non-noble elements from these alloys, and the surface composition appeared to be only one or two atomic layers thick. Of the three types of alloys, the high-gold alloy appeared to develop the most stable surface composition which released the lowest levels of elements.

\section{Introduction}

The release of elements from dental casting alloys into the oral cavity is a continuing concern because of the harmful biological effects that these elements may have on oral tissues. Reviewers (Lang, Morris \& Razzoog, 1985; Hensten-Pettersen, 1992) have concluded that further investigations are imperative to clarify the effects and side-effects of these alloys. Although the release of elements such as nickel (Ni), mercury $(\mathrm{Hg})$ or cadmium (Cd) from some dental alloys may approach the daily dietary intake of these elements (Brune, 1986), the release of elements such as gold $(\mathrm{Au})$, palladium $(\mathrm{Pd})$, silver $(\mathrm{Ag})$, copper $(\mathrm{Cu})$ or zinc $(\mathrm{Zn})$ from casting alloys are probably far below daily oral intake from other sources. Thus, the potential systemic effects of elements in casting alloys based on gold, palladium or silver are not generally a concern. However, the local effects of these elements are largely unknown in spite of evidence that they are potent disrupters of cellular metabolism (Wataha, Hanks \& Craig, 1991a; Hunt, Remes \& Williams, 1992) and are present in gingival tissues adjacent to restorations (Hao \& Lemons, 1989; Rechmann, 1992).

The concern about the effects of elements that are released from casting alloys has been intensified in recent years by the introduction of reduced-gold ( $<75$ wt. \% gold) or no-gold alloys. The use of these 'alternative' alloys approaches $70-80 \%$ of the market in the United States, despite evidence that they have 
corrosion properties that are inferior to their highgold counterparts (Mjör \& Hensten-Pettersen, 1983). Corrosion studies have documented that alternative alloys release more elements than traditional highgold alloys (Lappalainen \& Yli-Urpo, 1987; Johansson, Lemons \& Hao, 1989; Mezger et al., 1989). This greater elemental release is one reason that the biological safety of alternative alloys has been questioned.

Previous investigators have shown that the release of elements from many types of dental casting alloys is not necessarily proportional to the abundance of those elements in the alloy. This phenomenon has been called selective dissolution, since certain elements will be preferentially released from the alloy. Selective dissolution has been observed in binary alloys (Goehlich \& Marek, 1990), reduced-gold alloys (Niemi, Minni \& Ivaska, 1986), and high- and no-gold alloys (Wataha, Craig \& Hanks, 1991b). Because the nominal or bulk composition of the alloys has not been predictive of the amount of elemental release, the focus of interest has turned to the composition of the surface of the alloys as a predictor of elemental release. The composition of the surface may differ markedly from the bulk (Wataha, Craig \& Hanks, 1992), and elements that are more common at the surface have been shown in some cases to correlate with those that are released in vitro (Niemi et al., 1986; Goehlich \& Marek, 1990; Wataha et al., 1992).

There is limited information about how the surface layers of dental casting alloys change upon exposure to a biological fluid, how these changes correlate with elemental release, and how deeply the alloy is affected by the exposure. The surface layers of $\mathrm{Pd}-\mathrm{Cu}$ and $\mathrm{Pd}$-Co binary alloys have been shown to become enriched in $\mathrm{Pd}$, as the $\mathrm{Cu}$ and cobalt (Co) are released upon exposure to synthetic saliva (Goehlich $\delta$ Marek, 1990), and the surfaces of $\mathrm{Ag}-\mathrm{Pd}-\mathrm{Cu}-\mathrm{Au}$ alloys have been shown to become depleted in $\mathrm{Cu}$ and enriched in Pd and Ag (Niemi et al., 1986). However, these reports have not compared these observations with traditional high-gold casting alloys, and have not reported to what depth the surface composition differs from the layers below it. Depth profiles of the corrosion process have been reported for stainless steel that was exposed to saline and serum (Zabel et al., 1988), but no such data exists for dental casting alloys.

Therefore, the purpose of the current study was to determine the surface composition of high-, reducedand no-gold dental casting alloys upon exposure to a
Table 1. Composition of alloys (at. \%)

\begin{tabular}{lcccccl}
\hline Alloy & $\mathrm{Ag}$ & $\mathrm{Au}$ & $\mathrm{Cu}$ & $\mathrm{Pd}$ & $\mathrm{Zn}$ & Other \\
\hline High-gold & 11.5 & 49.8 & 31.5 & 2.6 & 3.2 & Pt 1.4 \\
Reduced-gold & 30.0 & 36.4 & 24.2 & 6.0 & 3.3 & \\
No-gold & 54.9 & 0 & 18.3 & 22.8 & 3.0 & $\mathrm{~B} 0.9, \mathrm{Ru} \mathrm{0.001}$ \\
\hline
\end{tabular}

$\mathrm{Ag}$, silver; $\mathrm{Au}$, gold; $\mathrm{Cu}$, copper; $\mathrm{Pd}$, palladium; $\mathrm{Zn}$, zinc; $\mathrm{Pt}$, platinum; $\mathrm{B}$, boron; $\mathrm{Ru}$, ruthenium.

biological fluid over time. It was attempted to identify those surface compositions that released the fewest elements and to measure how deeply the exposure affected the composition of the alloy. To accomplish this, the release of elements from these alloys was correlated with the compositions of the alloy surfaces over time. The composition of the surfaces was then determined as a function of depth. Identifying alloy compositions that promote or inhibit the release of elements by virtue of their surface compositions should help in the formulation of alloys that minimize the release of elements and, therefore, minimize biological risks.

\section{Materials and methods}

The alloys selected for this study were based on those that are commonly used in clinical practice (Table 1). The high-gold alloy was $49 \cdot 8$ at. \% Au (or approximately 75 wt.\% Au), plus $\mathrm{Cu}, \mathrm{Ag}, \mathrm{Pd}$ and $\mathrm{Zn}$. The reducedgold alloy contained 36.4 at. \% Au (about 56 wt.\% Au), and higher $\mathrm{Ag}$ than the high-gold alloy. The no-gold alloy was a multiple phase $\mathrm{Ag}-\mathrm{Pd}-\mathrm{Cu}$ alloy. The highand reduced-gold alloys were single phase alloys. Each sample was a disk $5.4 \mathrm{~mm}$ in diameter and $2.5 \mathrm{~mm}$ thick with a $1 \mathrm{~cm}$ stem attached to an unpolished face of the disk. The disk edges and opposite face were polished with Tripoli and rouge on $25 \mathrm{~cm}$ rag wheels rotating at 3200 revolutions per minute. Separate wheels and polishing compounds were used for each alloy to avoid cross contamination. After polishing, the samples were scrubbed with a polishing compound remover on a soft toothbrush, followed by scrubbing with a soap solution, then copious water rinses and ultrasonic treatment in $95 \%$ ethanol. Details for the cleaning procedures have been published previously (Wataha et al., 1992).

The release of elements from the alloys was measured by exposing the samples to $0.5 \mathrm{~mL}$ of cell-culture 
medium for 8 to $96 \mathrm{~h}$. The medium consisted of Dülbecco's Modified Eagle Medium with 3\% NuSerum, HEPES (28 mmol/L, pH 7.2), streptomycin (125 $\mu \mathrm{g} /$ $\mathrm{mL})$, penicillin ( 125 units $/ \mathrm{mL})$, gentamycin $(10 \mu \mathrm{g} / \mathrm{mL})$ and glutamine $(2 \mathrm{mmol} / \mathrm{L})$. There was $63 \mathrm{~mm}^{2}$ of alloy surface in contact with the cell-culture medium. Controls were disks of Teflon, and there were six replicates for each alloy. The alloys were incubated at $37{ }^{\circ} \mathrm{C}, 5 \% \mathrm{CO}_{2}$, and $95 \%$ relative humidity. After incubation, the medium was carefully removed and analysed for elements in the alloys by means of flame atomic absorption spectroscopy. The detection limits for $\mathrm{Ag}, \mathrm{Au}, \mathrm{Cu}, \mathrm{Pd}$ and $\mathrm{Zn}$ were 0.010, 0.045, 0.020, 0.020, and $0.010 \mu \mathrm{g} / \mathrm{mL}$, respectively. Specific conditions for the atomic absorption analysis have been reported previously (Wataha et al., 1991b). The samples were rinsed with water then dried before examination by electron microscopy.

The samples were viewed by scanning electron microscopy (SEM) and X-ray photoelectron spectroscopy (XPS) before and after exposure to the medium. SEM samples were viewed at 25.0 and $1000 \times$ at $20 \mathrm{kV}$. XPS samples were analysed using a magnesium $(\mathrm{Mg})$ $\mathrm{X}$-ray source at $15 \mathrm{kV}$ and $300 \mathrm{~W}$. Two samples of each alloy were analysed. For XPS analysis, only $\mathrm{Ag}, \mathrm{Cu}, \mathrm{Pd}$ and $\mathrm{Au}$ were measured since these elements composed the majority of the alloy mass or had been shown to be the elements which were released into the medium. For depth studies, carbon (C) content was also measured as a marker for the presence of the organic components of the medium. To obtain composition as a function of depth, the surface of the alloy was etched with argon (Ar) at $10 \mathrm{mPa}$ accelerated at $3 \mathrm{kV}$ and $25 \mathrm{~mA}$ for times between 6 and $156 \mathrm{~s}$. To calibrate the depth of the etching for a given time, tantalum pentoxide $\left(\mathrm{Ta}_{2} \mathrm{O}_{5}\right)$ with a known thickness of $1000 \AA$ was etched in one minute intervals until the oxide was penetrated. The atomic concentrations of elements on the alloy surfaces were calculated by dividing the peak area (minus background) by the sensitivity factor for each element, then computing this quotient as a percentage of the total of all adjusted peak areas (Briggs $\&$ Seah, 1983). The errors in the atomic concentrations were between 5 and $20 \%$ based upon literature (Briggs \& Seah, 1983) and repeated measurements in selected cases.

\section{Results}

The high-gold alloy released primarily $\mathrm{Cu}$, but low levels of $\mathrm{Zn}$ were also detected (Fig. 1a). The majority
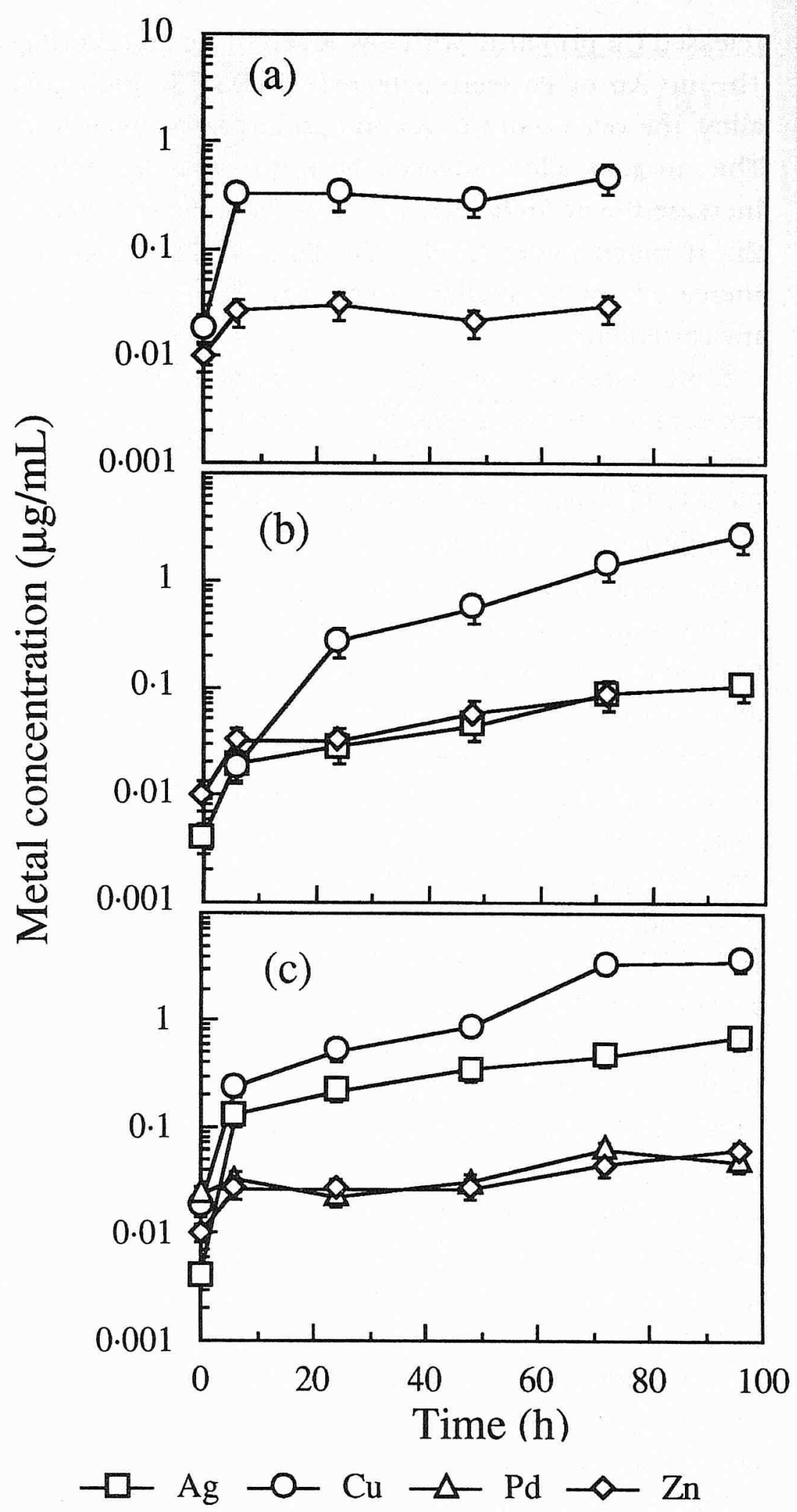

Fig. 1. Elemental release from (a) high-gold, (b) reduced-gold, and (c) no-gold dental casting alloys into $0.5 \mathrm{~mL}$ of cell-culture medium between 8 and $96 \mathrm{~h}$; the surface area of the alloy exposed to the medium was $63 \mathrm{~mm}^{2}$; the detection limits of the elements were $0.010,0.045,0.020,0.020$ and $0.010 \mu \mathrm{g} / \mathrm{mL}$ for $\mathrm{Ag}, \mathrm{Au}, \mathrm{Cu}$, $\mathrm{Pd}$ and $\mathrm{Zn}$, respectively; error bars represent three standard errors of the means of $n=6$; elements which are not shown were not detected around the alloys.

of the dissolution occurred within the first $8 \mathrm{~h}$ of exposure to the medium, and there was little additional release after $8 \mathrm{~h}$. Au, Pd or $\mathrm{Ag}$ were not detected in the medium around this alloy. The reduced-gold alloy 
released $\mathrm{Cu}$ primarily with low levels of $\mathrm{Ag}$ and $\mathrm{Zn}$ (Fig. Ib); no $\mathrm{Au}$ or Pd were detected. Unlike the high-gold alloy, the release of $\mathrm{Cu}, \mathrm{Ag}$ and $\mathrm{Zn}$ increased over $96 \mathrm{~h}$. The no-gold alloy released both $\mathrm{Cu}$ and $\mathrm{Ag}$, which increased over $96 \mathrm{~h}$ (Fig. 1c), and also released Pd and $\mathrm{Zn}$ at much lower levels. The $\mathrm{Pd}$ and $\mathrm{Zn}$ dissolution increased only slightly over the $96 \mathrm{~h}$ period of measurement.

SEM analysis revealed no differences in the appearance of the alloys up to $1000 \times$ magnification before or after exposure to the cell-culture medium, even when exposure continued for up to 30 days. In addition, no differences between the exposed and unexposed alloys could be seen by eye.

XPS analysis of the high-gold alloy surface showed that before exposure to the medium, the surface was about 45 at. $\% \mathrm{Au}, 10 \% \mathrm{Ag}$ and $45 \% \mathrm{Cu}$ (Fig. 2a). After exposure to the medium for $8 \mathrm{~h}$, the surface composition changed significantly. Au concentration increased to nearly 80 at. \%, while $\mathrm{Ag}$ increased slightly to $15 \%$ and $\mathrm{Cu}$ decreased to less than $5 \%$. After $96 \mathrm{~h}$ of exposure to the cell-culture medium, the alloy surface was still rich in $\mathrm{Au}(70 \%)$, with about $20 \% \mathrm{Ag}$ and $10 \% \mathrm{Cu}$. The reduced-gold alloy surface had an initial composition of $45 \% \mathrm{Au}, 20 \% \mathrm{Ag}$ and $35 \% \mathrm{Cu}$ (Fig. 2b). Upon exposure to the medium for $8 \mathrm{~h}$, the $\mathrm{Au}$ increased slightly to $50 \%$, while the Ag increased to nearly $40 \%$ and the $\mathrm{Cu}$ dropped to $10 \%$. The surface composition after $96 \mathrm{~h}$ exposure to the medium was similar to that at $8 \mathrm{~h}$. The no-gold alloy surface had an initial composition of 25 at. \% Pd, 60\% Ag, and 15\% Cu (Fig. 2c). After exposure to the medium for $8 \mathrm{~h}$, the $\mathrm{Ag}$ concentration increased to $70 \%$ and the $\mathrm{Cu}$ concentration dropped to $5 \%$. The Pd concentration was unchanged. After $96 \mathrm{~h}$ exposure, the surface was $25 \% \mathrm{Pd}, 65 \% \mathrm{Ag}$, and $10 \% \mathrm{Cu}$.

The depth of the effect of the cell-culture medium varied with the alloy. For the high-gold alloy, carbon could be detected beyond $80 \AA$ after $96 \mathrm{~h}$ of exposure, but was most prevalent in the first $30 \AA$ (Fig. 3a). For the reduced-gold alloy, carbon content was about 25 at. \% of all elements to depths below $80 \AA$ (Fig. 3b), whereas significant carbon was restricted to the first $30 \AA$ of the no-gold alloy (Fig. 3c). The surface composition differed significantly from the composition of the alloy as little as $5 \AA$ below the surface (Fig. 4). After $8 \mathrm{~h}$ of exposure to the cell-culture medium, the surface of the high-gold alloy contained $20 \%$ less $\mathrm{Cu}, 5 \%$ more $\mathrm{Ag}$, and $20 \%$ more gold than the alloy at a depth of just $5 \AA$. The surface of the reduced-gold alloy was richer

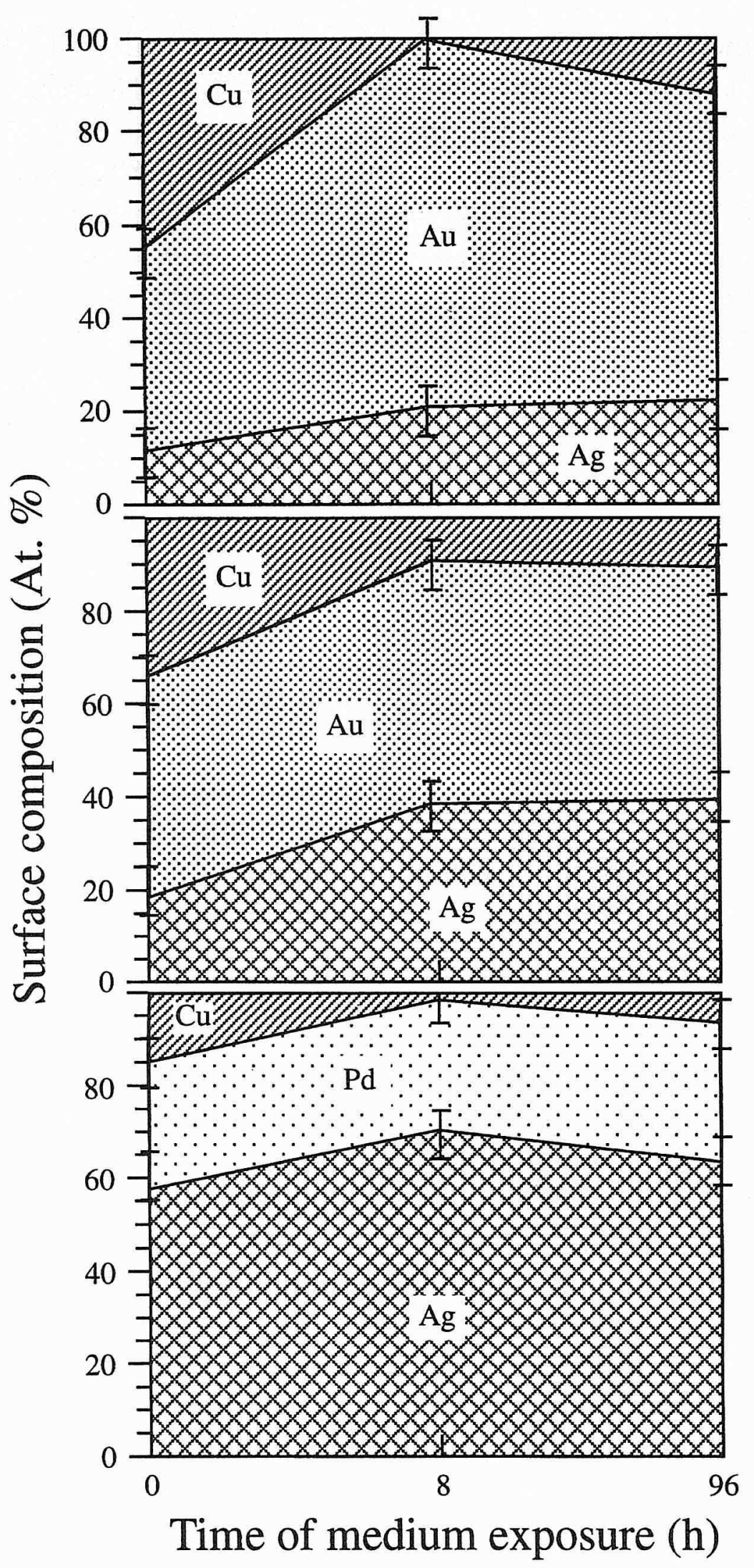

Fig. 2. X-ray photoelectron spectroscopic (XPS) analysis of the surface layers of the high-gold (top), reduced-gold (middle), and no-gold (bottom) alloys as a function of time of exposure to the cell-culture medium; errors in the measurements are approximately $10 \%$.

in $\mathrm{Au}$, poorer in $\mathrm{Cu}$, and similar in $\mathrm{Ag}$ abundance as the composition at a $5 \AA$ depth. The no-gold alloy was richer in $\mathrm{Ag}$ at the surface, but poorer in $\mathrm{Cu}$, whereas the Pd content was unchanged. 

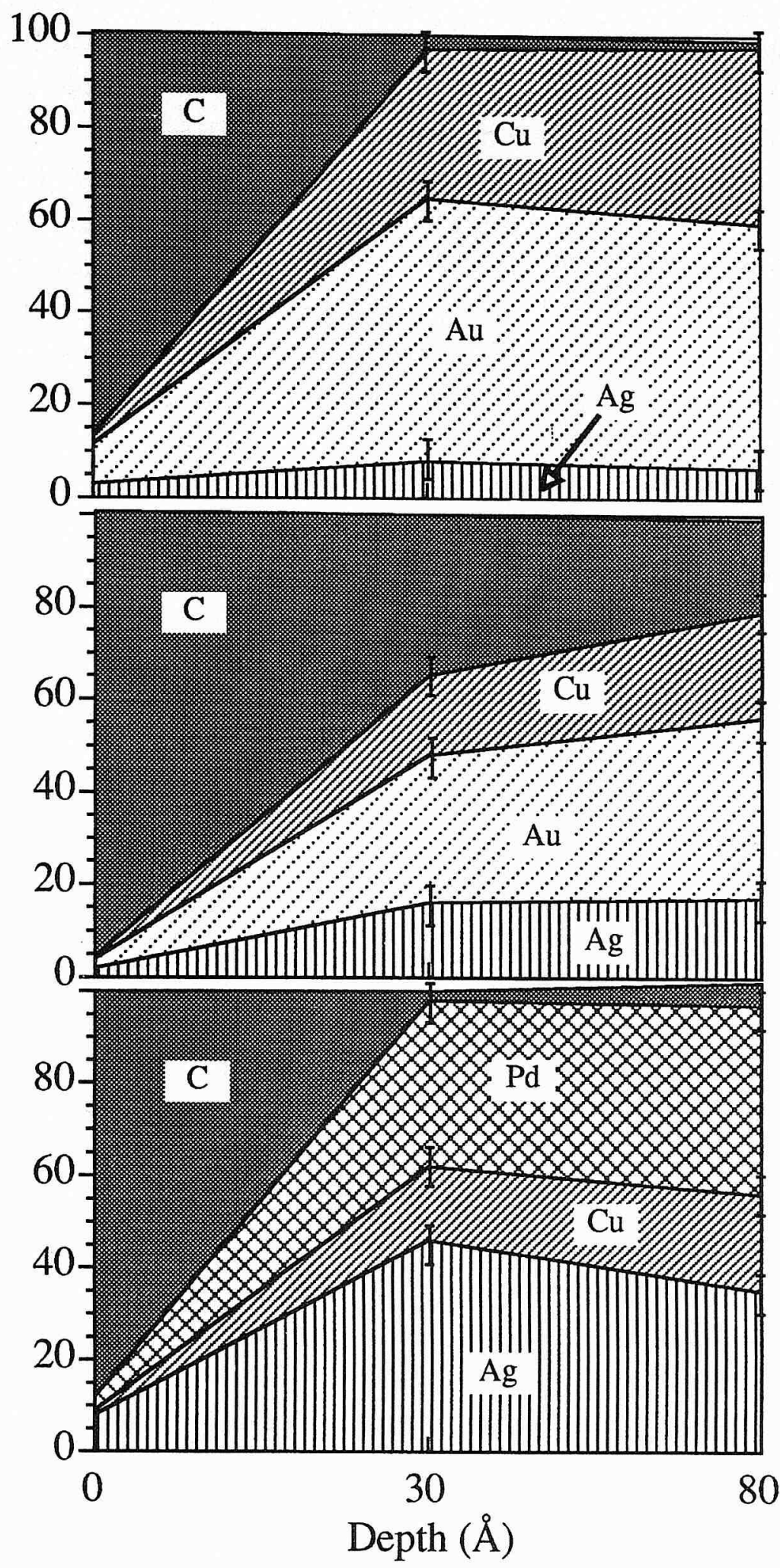

Fig. 3. XPS analysis of the surface layers of the high-gold (top), reduced-gold (middle) and no-gold (bottom) alloys after argon milling the surface from 0 to $80 \AA$; errors in the measurements are approximately $10 \%$; all alloys were exposed to the medium for $96 \mathrm{~h}$.

\section{Discussion}

Release of elements from the surfaces of these alloys occurred when the proportion of relatively non-noble elements like $\mathrm{Ag}$ or $\mathrm{Cu}$ was greater than or equal to the proportion of more noble elements like $\mathrm{Au}$ or Pd. For the high-gold alloy, the ratio of noble to non-noble elements before exposure to the cell-culture medium

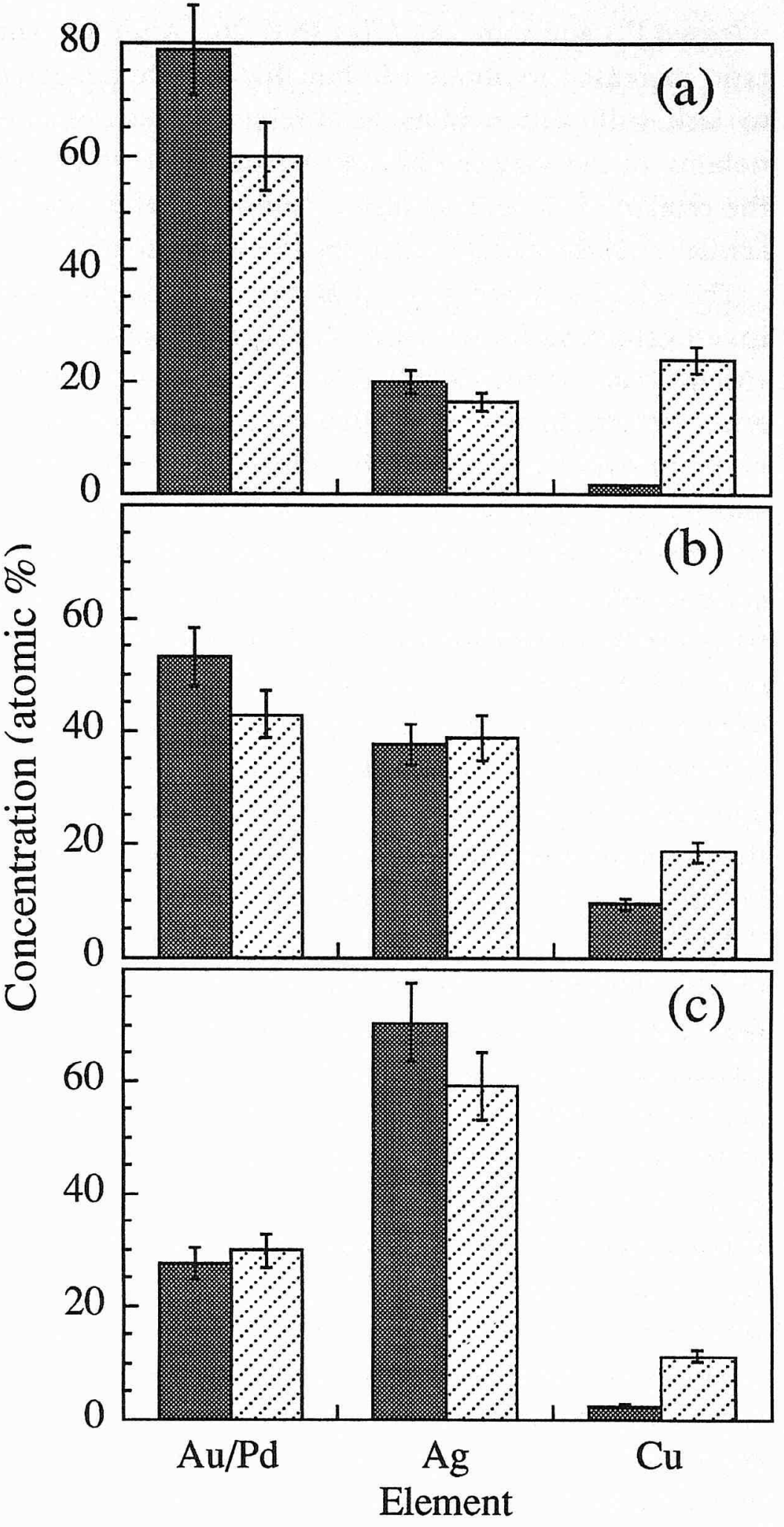

Fig. 4. Comparison between the surface composition (dark columns) and composition $5 \AA$ below the surface (light columns) for the (a) high-gold, (b) reduced-gold, and (c) no-gold alloys after exposure to cell-culture medium for $8 \mathrm{~h}$; error bars show a $10 \%$ error.

was $0 \cdot 8$, indicating a greater proportion of non-noble elements at the surface (Fig. 2a). Under these conditions, the alloy released $\mathrm{Cu}$ into the medium (Fig. la). After $8 \mathrm{~h}$, the ratio increased to over $3 \cdot 0$, reflecting a greater proportion of $\mathrm{Au}$. At this time, $\mathrm{Cu}$ dissolution stopped. These ratios were essentially unchanged throughout the $96 \mathrm{~h}$ period. For the reduced-gold alloy, the initial noble to non-noble ratio was about $0 \cdot 8$, when the alloy 
released $\mathrm{Cu}$ and some $\mathrm{Ag}$ (Figs $\mathrm{lb} \& 2 \mathrm{~b}$ ). After $8 \mathrm{~h}$, the ratio increased to about $1 \cdot 0$, but this surface appeared to lack sufficient nobility to inhibit $\mathrm{Cu}$ release. The nobility of the surface did not increase after $96 \mathrm{~h}$, and the release of $\mathrm{Cu}$ and $\mathrm{Ag}$ also continued at this time. A similar analysis can be made for the no-gold alloy.

The selective dissolution reported previously by other investigators was observed in the current study as well (Niemi et al., 1986, Goehlich \& Marek, 1990, Wataha et al., 1991b). In spite of the high concentrations of $\mathrm{Au}$ or Pd in these alloys, little or none of these elements was released into the cell-culture medium. In addition, the amount of $\mathrm{Cu}$ released was high relative to its concentration in the alloys. This observation was particularly true for the no-gold alloy, which contained only 18 at.\% $\mathrm{Cu}$, but released more $\mathrm{Cu}$ than any other element. The phenomenon of selective dissolution seemed to rely on the relative nobility of the elements and their abundance at the surface of the alloys. Thus, the presence of an element at the surface was necessary but not sufficient to cause dissolution.

The depth of the effect of the cell-culture medium on the alloy surface did not necessarily correlate with the quantity of elements released. For the reduced-gold alloy, the surface was altered to at least $80 \AA$, which correlated with the relatively large quantities of elements (primarily $\mathrm{Cu}$ ) which were released (Figs $\mathrm{lb}$ $\varepsilon 3 b)$. For the high-gold alloy, the effect of the medium was restricted to the first $30 \AA$, which correlated with the small quantities of $\mathrm{Cu}$ which were released. However, the no-gold alloy, which released the largest quantities of elements of the three alloys, also showed surface changes restricted to only $30 \AA$. The exceptional behaviour of the no-gold alloy may have been caused by its multiple phase microstructure. The effect of the medium may not have been deeper than $30 \AA$ in areas of high nobility, but local areas of non-noble elements could have been effected more deeply. The different depths would be averaged by XPS, which accumulated data from a relatively large $\left(1.4 \mathrm{~mm}^{2}\right)$ area of the alloy. Analysis of the surface with Auger spectroscopy could test this hypothesis because analysis could be restricted to one phase. It is important to remember that the original surface may be altered by a deposition of mass, a loss of mass, or both. Thus, with the reduced-gold alloy, the presence of carbon $80 \AA$ into the alloy may not necessarily mean that the original surface of the alloy was affected to a depth of $80 \AA$. The depth profile in Fig. $3 \mathrm{~b}$ may be a product of the build-up of corrosion products on the original surface combined with a loss of mass. It is impossible to characterize which processes occurred from the data of the current study.

The observation that the composition of the surface is significantly different from that $5 \AA$ below the surface indicates that surfaces that inhibit or permit elemental release are probably quite thin. Since the metallic diameters of the transition elements in dental casting alloys are approximately $3 \AA$ (Purcell \& Kotz, 1977), these surfaces may only be one or two atomic layers thick. It seems likely that a gradient of compositions exists, from the surface to the nominal composition in the bulk. The results of the current study and those of our previous work indicate that the thickness of this gradient is probably less than $100 \AA$ even when significant elemental release occurs (Wataha et al., 1992). From a qualitative standpoint, these thin surface gradients are consistent with visual and SEM observations that these alloys do not look different even after several months in cell-culture medium.

The no-gold alloy in the current study functioned similarly to alloys with similar composition used by previous investigators (Niemi et al., 1986). Both alloys showed a depletion of $\mathrm{Cu}$ and enrichment of $\mathrm{Ag}$ at the surface. The depletion of Pd noted by previous investigators was not observed in the current study. The data from the current study as well as those of previous studies seems to leave little doubt that the surface compositions of dental casting alloys are significantly different from their bulk compositions (Niemi et al., 1986; Wataha et al., 1992).

Previous studies have reported that Pd will limit the dissolution of $\mathrm{Cu}$ in $\mathrm{Pd}-\mathrm{Cu}$ alloys if the concentration of Pd relative to $\mathrm{Cu}$ is greater than 30 at.\% (Goehlich \& Marek, 1990; J.C. Wataha \& R.G. Craig, unpublished observations). The inhibition of $\mathrm{Cu}$ release is probably caused by an enrichment of Pd at the surface after a short equilibration time. Although the concentration of Pd in the no-gold alloy in the current study was $>30$ at.\% relative to $\mathrm{Cu}$, significant dissolution of $\mathrm{Cu}$ was observed. It is possible that $\mathrm{Cu}$-containing phases in the alloy contained insufficient $\mathrm{Pd}$ to inhibit $\mathrm{Cu}$ release. EDS analysis of SEM samples indicated that at least one phase of this alloy was relatively rich in $\mathrm{Cu}$ (52 at.\%) relative to the nominal composition (Table 1 ). This $\mathrm{Cu}$ rich phase may have the major source of the $\mathrm{Cu}$ which was released. However, since the EDS measures elemental concentrations well below the surface, its usefulness is questionable. Auger anlaysis would be 
most useful in this regard, and should be used in future studies.

\section{Acknowledgments}

The authors thank Chris Edwards for his expert advice with the scanning electron microscopy, Hal Estry for his help with the X-ray photoelectron spectroscopy, and Dr Richard Corpron for allowing us to use the atomic absorption spectrophotometer. We also thank Delta Dental of Michigan and the National Institutes of Health (NIDR DE-09296) for their support of our research.

\section{References}

BRIGGS, D. \& SEAH, M.P., editors (1983) Practical surface analysis, Chapter I. John Wiley and Sons, New York.

BRUNE, D. (1986) Metal release from dental biomaterials. Biomaterials, 7, 163.

Goenlich, V. \& MAReK, M. (1990) Corrosion behavior of Pd-Cu and Pd-Co alloys in synthetic saliva. Dental Materials, 6, 103.

HAO, S.Q. \& Lemons, J.E. (1989) Histology of dog dental tissues with Cu-based crowns. Journal of Dental Research, 68, 322 (Abstr. No. 1125).

Hensten-Pettersen, A. (1992) Casting alloys: side effects. Advances in Dental Research, 6, 38.

Hunt, J.A., Remes, A. \& Williams, D.F. (1992) The effect of metal ions on neutrophil degranulation. Journal of Materials Science: Materials in Medicine, 3, 192.

Johansson, B.I., Lemons, J.E. \& HaO S.Q. (1989) Corrosion of dental copper, nickel, and gold alloys in artificial saliva and saline solutions. Dental Materials, 5, 324.

LANG, B.R., Morris, H.F. \& RazzoOG, M.E., editors (1985)
International workshop: biocompatibility, toxicity, and hypersensitivity to alloy systems used in dentistry. Univ. of MI Press, Ann Arbor.

LAPPALAinen, R. \& YLI-URPo, A. (1987) Release of elements from some gold alloys and amalgams in corrosion. Scandinavian Journal of Dental Research, 95, 364.

Mezger, P.R., Stols, A.L.H., VRiJhoef, M.M.A. \& Greener, E.H. (1989) Metallurgical aspects and corrosion behavior of yellow low-gold alloys. Dental Materials, 5, 350.

MJör, I.A. \& Hensten-PetTersen, A. (1983) The biological compatibility of alternative alloys. International Dental Journal, 33,35 .

Niemi, L., Minni, E. \& Ivaska, A. (1986) An electrochemical and multispectroscopic study of corrosion of Ag-Pd-Cu-Au alloys. Journal of Dental Research, 65, 888.

PuRCELl, K.F. \& KOTZ, J.C. (1977) Inorganic chemistry, p.528. WB Saunders Co., London.

RECHMANN, P. (1992) LAMMS and ICP-MS detection of dental metallic compounds in not-discoloured human gingiva. Journal of Dental Research, 71, 599 (Abstr. No. 672).

WATAha, J.C., HANKS, C.T. \& CRAIG, R.G. (1991a) The in vitro effects of metal cations of eukaryotic cell metabolism. Journal of Biomedical Materials Research, 25, 1133.

Wataha, J.C., Craig, R.G. \& Hanks, C.T. (1991b) The release of elements of dental casting alloys into cell-culture medium. Journal of Dental Research, 70, 1014.

Wataha, J.C., Craig, R.G. \& Hanks, C.T. (1992) The effects of cleaning on the kinetics of in vitro metal release for dental casting alloys. Journal of Dental Research, 71, 1417.

Zabel, D.D., Brown, S.A., Merritt, K. \& Payer, J.H. (1988) AES (auger electron spectroscopy) of stainless steel corroded in saline, in serum and in vivo. Journal of Biomedical Materials Research, 22, 31 .

Correspondence: Dr John C. Wataha, Department of Oral Rehabilitation, School of Dentistry, Medical College of Georgia, Augusta, Georgia, 30912-1260, U.S.A. 
This document is a scanned copy of a printed document. No warranty is given about the accuracy of the copy. Users should refer to the original published version of the material. 